\title{
Achalasia: outcome of patients treated with intrasphincteric injection of botulinum toxin
}

\author{
C Cuillière, P Ducrotté, F Zerbib, E H Metman, D de Looze, F Guillemot, H Hudziak, \\ H Lamouliatte, J C Grimaud, A Ropert, M Dapoigny, R Bost, M Lémann, M A Bigard, \\ P Denis, J L Auget, J P Galmiche, S Bruley des Varannes
}

University Hospital Centre, Nantes, France

C Cuillière

$\mathrm{J}$ L Auget

J P Galmiche

S Bruley des Varannes

University Hospital Centre, Rouen, France P Ducrotté

$P$ Denis

University Hospital Centre, Bordeaux, France

F Zerbib

H Lamouliatte

University Hospital Centre, Tours, France

E H Metman

University Hospital Centre, Lille, France F Guillemot

University Hospital Centre, Nancy, France H Hudziak

M A Bigard

University Hospital Centre, Marseille, France

J C Grimaud

University Hospital Centre, Rennes, France

A Ropert

University Hospital Centre, Clermont Ferrand, France

M Dapoigny

University Hospital Centre, Grenoble, France

$R$ Bost

University Hospital Centre, Paris, France M Lémann

University Hospital Centre, Ghent,

Belgium

D de Looze

Correspondence to:

Dr S Bruley des Varannes, Hôpital Laënnec, 44035 Nantes Cedex, France.

Accepted for publication 28 January 1997

\begin{abstract}
Background-To evaluate the safety and clinical efficacy of botulinum toxin (BT) in patients with achalasia followed up for six months.
\end{abstract}

Methods-Fifty five symptomatic patients with manometrically proven achalasia were included in a multicentre prospective trial. Before and two weeks and two months after intrasphincteric injection of BT, symptoms of dysphagia, regurgitation, and chest pain were scored on a 0-3 scale, and lower oesophageal sphincter pressure (LOSP) was assessed. The symptom score was determined again at six months, clinical improvement being defined by $\leq 3$, relapse by $>3$, and failure as a relapse after two injections or loss to follow up.

Results-Except for transient chest or epigastric pain $(22 \%)$, no side effects were observed. There was a significant decrease in LOSP after treatment. Symptom scores were significantly improved at two weeks $(2 \cdot 0$ (SD 1.6)), two months $(1 \cdot 7(1 \cdot 8))$, and six months $(1.9(2 \cdot 0))$ compared with pretreatment values $(5 \cdot 1(1 \cdot 8), p<0 \cdot 001)$. At six months, 33 patients had clinical improvement ( 27 after one injection), 17 were considered failures, and five had just relapsed. Although there was a trend for age (older patients being more responsive), age, sex, prior duration of symptoms, initial symptom score, weight loss, LOSP, magnitude of oesophageal contractions, vigorous or non-vigorous achalasia, previous dilatations, and radiological features were not predictive of results.

Conclusions-This multicentre series confirms that intrasphincteric injection of BT is a safe procedure, resulting in clinical improvement in $60 \%$ of patients with achalasia at six months. The therapeutic role of BT in achalasia needs further evaluation with regard to other alternatives.

(Gut 1997; 41: 87-92)

Keywords: achalasia; botulinum toxin; oesophageal motor disorders

Achalasia is a well defined primary oesophageal motor disorder characterised by a lack of peristalsis and a hypertonic lower oesophageal sphincter (LOS), with incomplete relaxations. ${ }^{1}$ Treatment modalities consist of cardio- myotomy and pneumatic dilatation, both of which are intended to relieve functional obstruction of the distal oesophagus. The symptomatic efficacy of these treatments ranges from $60 \%$ to $80 \% .^{2-7}$ The risk of perforation after dilatation is estimated to be $1-6 \% .^{5}$ Mortality related to these treatments is about $0 \cdot 2 \%{ }^{67}$

Intrasphincteric injection of botulinum toxin (BT) has been recently proposed as an alternative to pneumatic dilatation or surgery in the treatment of achalasia. ${ }^{8-10} \mathrm{BT}$ has been shown to inhibit acetylcholine release from nerve endings, thereby inducing muscular paresis. ${ }^{11-13}$ The effect of BT is reversible due to the sprouting of terminal axons that form new synaptic contacts on adjacent muscle fibres. ${ }^{14}$ BT has been used therapeutically in diseases producing hypertonia of skeletal muscles, ${ }^{11}{ }^{13}{ }^{15}$ but its use in smooth muscle is very recent. In vitro studies have shown that BT is also able to inhibit electrically stimulated smooth muscle contraction by blocking the presynaptic release of acetylcholine, without affecting the non-adrenergic non-cholinergic response. ${ }^{16} 17$ Pasricha et al showed that injection of BT into the LOS of piglets strongly decreased resting LOS tone..$^{18}$ In a single centre trial, this same group recently reported that BT can be used for the treatment of achalasia. Their initial experience showed a $64 \%$ improvement rate (20/31 patients) at six months. ${ }^{8-10}$ However, it has not yet been clearly established whether these results can be reproduced in less specialised centres and in conditions of routine practice.

In this context, we conducted a prospective multicentre study of BT in achalasia in order to assess the feasibility of treatment as well as to provide additional data on its efficacy and safety.

\section{Patients and methods}

PATIENTS

The diagnosis of achalasia was manometrically determined on the basis of complete aperistalsis, together with either hypertonia of the LOS or incomplete relaxations of the LOS. ${ }^{1}$ Symptomatic patients with achalasia (as defined above) were included. Patients under 18 years of age or over 80 , pregnant or breastfeeding women, patients with previous oesophageal myotomy or those with secondary achalasia, and patients in whom BT was contraindicated (those using antibiotics, myorelaxants, or curare, or those with muscular 
disorders or severe ulcerative oesophagitis ( $\geqslant$ grade 2 in the Savary-Miller classification)) were excluded.

The study was approved by the Ethics Committee of Nantes (Centre de Protection des Personnes des Pays de Loire Numéro 2), and written informed consent was obtained from all patients.

STUDY DESIGN AND PROCEDURE (fig 1)

The study was designed as a multicentre (12 centres) prospective open trial. During the month before BT injection, patients underwent a pretherapeutic work up including clinical assessment, oesophageal manometry, 24 hour $\mathrm{pH}$ monitoring, and oesophagography. Endoscopic ultrasonography $(n=18)$ was performed only when the clinician considered that secondary achalasia had to be excluded. ${ }^{19} 20$

Oesophageal manometry was performed after an overnight fast according to the method customarily used in each centre (a multilumen manometric catheter perfused by a low-compliance pneumohydraulic capillary infusion system). When it proved impossible to pass the manometric probe through the LOS, it was placed endoscopically. LOS pressure was determined by the slow pull-through method. Before each swallow, the patient was given 5 $\mathrm{ml}$ of water in the mouth. Resting mean LOS pressure was determined by calculating the mean of end expiratory readings recorded on each opening, both in abdominal and thoracic segments, under and above the pressure inversion point, respectively. LOS relaxation was determined by calculating the percentage of relaxations after each swallow (complete, incomplete, or absent). Gastric pressure was established as zero baseline, and the degree of relaxation of LOS was determined by reference to this baseline. A relaxation of $80 \%$ was considered complete. Finally, the amplitude of swallow induced waves in the oesophageal body was measured. Vigorous achalasia was considered to be present when the mean amplitude of pressure waves in the oesophageal body was $>30 \mathrm{~mm} \mathrm{Hg}$. This value corresponded to the lower limit of normal adopted by all centres.

For the procedure, patients were hospitalised for 24 hours. Botulinum toxin (Botox ${ }^{\circledR}$, Allergan France, Mougins, France) was injected following an overnight fast, either with (propofol, Diprivan ${ }^{\circledR}$, ICI Pharma, Cergy, France) $(n=25)$ or without general anaesthesia $(n=30)$. Before BT injection, complete flexible

\begin{tabular}{|c|c|c|c|c|}
\hline Inclusion & $\begin{array}{c}\text { Botox } \\
20 U \times 4\end{array}$ & Additic & tion (w) & ssary) \\
\hline 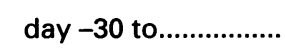 & day 0 & day 15 & day 60 & day 180 \\
\hline $\begin{array}{l}\text { Symptom score } \\
\text { Manometry } \\
\text { Scintigraphy } \\
\text { pH-metry }\end{array}$ & $\begin{array}{l}+ \\
+ \\
+ \\
+\end{array}$ & $\begin{array}{l}+ \\
+ \\
+ \\
+\end{array}$ & $\begin{array}{l}+ \\
+ \\
+ \\
+\end{array}$ & + \\
\hline
\end{tabular}

Figure 1: Trial design. upper gastrointestinal endoscopy was performed. BT was injected through a sclerotherapy needle (TW IV $6 \mathrm{c}$, length $6 \mathrm{~mm}$, diameter $0.7 \mathrm{~mm}, \mathrm{ABS}$, St Dié, France) into the four quadrants of the LOS $(20 \mathrm{U} / \mathrm{ml}$ saline, total dose $80 \mathrm{U}$ ). To rinse the residual volume from the needle $(0.5 \mathrm{ml})$, an additional injection of $1 \mathrm{ml}$ of saline was performed after each BT injection. The patient was allowed to eat on the following day.

\section{FOLLOW UP VISITS}

Visits were systematically scheduled at two weeks and two and six months after BT injection (fig 1). In patients who showed no (or insufficient) improvement two weeks after the first injection, as well as in those whose symptoms recurred during the six month follow up, a second injection was proposed (using the same procedure). If symptoms recurred after the second injection, patients were withdrawn and considered to be failures.

\section{CLINICAL ASSESSMENT}

Symptomatic response was evaluated using a modified score according to Eckardt et al, ${ }^{3}$ which was the sum of the individual scores for dysphagia, regurgitation, and chest pain (table 1). An adjectival scale of therapeutic efficacy was also proposed to patients who chose between "excellent", "good", "tolerable", and "bad", according to their own perceptions.

In addition to undergoing immediate follow up after injections, patients were questioned about the occurrence of potential side effects from the injections, especially fever, symptoms of gastro-oesophageal reflux, and chest pain.

\section{ADDITIONAL PROCEDURES}

Two weeks and two months following injection, LOS pressure was manometrically measured, and 24 hour $\mathrm{pH}$ monitoring was performed. In addition, in two centres, the isotopic oesophageal emptying fraction was determined for solids and liquids (fig 1).

\section{Oesophageal pH monitoring}

Twenty four hour $\mathrm{pH}$ monitoring was conducted according to the usual procedures of each centre. After nasal introduction, the electrode was placed $5 \mathrm{~cm}$ above the LOS, which had been previously located by manometry. Oesophageal acid exposure was expressed as the percentage of total time below $\mathrm{pH} \mathrm{4}$, with a cut-off value $4 \cdot 2 \%$ above $\mathrm{pH} 4$ as the upper limit of normality.

TABLE 1 Grading score for the evaluation of clinical symptoms in patients with achalasia (from Eckardt et $\mathrm{al}^{3}$ )

\begin{tabular}{llll}
\hline Score & Dysphagia & Retrosternal pain & Regurgitation \\
\hline 0 & None & None & None \\
1 & Occasional & Occasional & Occasional \\
2 & Daily & Daily & Daily \\
3 & Each meal & Each meal & Each meal \\
\hline
\end{tabular}


Oesophageal scintigraphy

This was performed in two centres after an overnight fast. With the patient seated in front of the gamma camera, imaging was done from the oropharynx to the cardia in anterior projection. The patient was first given $10 \mathrm{ml}$ saline containing $300 \mu \mathrm{Ci}$ of technetium-99m labelled sulphocolloid p.o., after which the liquid emptying fraction was measured after one and eight minutes. The patient then swallowed $1 \mathrm{~g}$ of pate radiolabelled with $1 \mathrm{mCi}$ of ${ }^{99 \mathrm{~m}} \mathrm{Tc}$, after which the solid emptying fraction was measured after one and eight minutes.

STATISTICS

The primary end point - that is, the percentage of patients still in clinical improvement at six months, was analysed on an intention to treat (ITT) basis. Patients were classified into three

\begin{tabular}{|c|c|}
\hline $\begin{array}{l}\text { Age (y) median (range) } \\
\text { Sex }(M / F)\end{array}$ & $\begin{array}{l}53(19-78) \\
28 / 27\end{array}$ \\
\hline Previous pneumatic dilatation & \\
\hline $\begin{array}{l}\text { No of patients }(\%) \\
\text { Median of dilatations (range) }\end{array}$ & $\begin{array}{l}18(33) \\
1(1-12)\end{array}$ \\
\hline \multicolumn{2}{|l|}{ Symptoms } \\
\hline Dysphagia (\%) & $55(100)$ \\
\hline Regurgitation (\%) & $46(83)$ \\
\hline Chest pain (\%) & $32(58)$ \\
\hline $\begin{array}{l}\text { Prior duration of symptoms (months) mean } \\
\text { (SD) }\end{array}$ & $39(47)$ \\
\hline Mean symptom score (SD) & $5 \cdot 1(1 \cdot 8)$ \\
\hline Clinical status & \\
\hline $\begin{array}{l}\text { Weight }(\mathrm{kg}) \text { mean }(\mathrm{SD}) \\
\text { No of patients with weight loss }>1 \mathrm{~kg}(\%)\end{array}$ & $\begin{array}{l}66 \cdot 5(14 \cdot 0) \\
37(67)\end{array}$ \\
\hline Weight losst (kg) mean (range) & $8 \cdot 8(1-27)$ \\
\hline \multicolumn{2}{|l|}{ Oesophageal function } \\
\hline Lower sphincter pressure $(\mathrm{mm} \mathrm{Hg})$ mean $(\mathrm{SD})$ & $27(12)$ \\
\hline Amplitude of waves ( $\mathrm{mm} \mathrm{Hg}$ ) mean (SD) & $37(33)$ \\
\hline Vigorous achalasia/classic achalasia (n/n) & $22 / 33$ \\
\hline $\begin{array}{l}\text { Mean fractional emptying of solids at } 1 \mathrm{~min} \\
(\mathrm{SD})^{\star}\end{array}$ & $41(31) \%$ \\
\hline $\begin{array}{l}\text { Mean fractional emptying of liquids at } 1 \mathrm{~min} \\
(\mathrm{SD})^{\star}\end{array}$ & $39(30) \%$ \\
\hline $\begin{array}{l}\text { No of patients with abnormal acid exposure } \\
(\%)\end{array}$ & $2 / 42(5 \%)$ \\
\hline Oesophageal diameter $(\mathrm{cm})$ mean $(\mathrm{SD})$ & $4 \cdot 4(1 \cdot 5)$ \\
\hline
\end{tabular}

TABLE 3 Results of intrasphincteric injection of botulinum toxin on symptoms at week 2 and months 2 and 6

\begin{tabular}{|c|c|c|c|c|}
\hline & Baseline & Week 2 & Month 2 & Month 6 \\
\hline \multicolumn{5}{|c|}{ Intention to treat analysis $(n=55)$} \\
\hline Clinical improvement & & 75 & 69 & 60 \\
\hline Failure & & 25 & 31 & 40 \\
\hline \multicolumn{5}{|l|}{ Subjective score $(\%)^{\mathrm{a}}$} \\
\hline Excellent - good & & 73 & 71 & 58 \\
\hline Tolerable - bad & & 27 & 29 & 42 \\
\hline \multicolumn{5}{|l|}{ Per protocol analysis } \\
\hline & & $(n=55)$ & $(n=53)$ & $(n=51)$ \\
\hline Clinical improvement & & 75 & 72 & 65 \\
\hline Failure & & 25 & 28 & 35 \\
\hline \multicolumn{5}{|l|}{ Subjective score $(\%)^{\mathrm{a}}$} \\
\hline $\begin{array}{l}\text { Excellent - good } \\
\text { Tolerable - bad }\end{array}$ & & 73 & 74 & 63 \\
\hline Tolerable - bad & & & 26 & 37 \\
\hline Mean symptom score (SD) & $(\mathrm{n}=55)$ & $(n=55)$ & $(n=49)$ & $(n=40)$ \\
\hline Dysphagia & $2 \cdot 6(0 \cdot 6)$ & $1 \cdot 0(1 \cdot 0)^{\star \star \star}$ & $1 \cdot 0(1 \cdot 0)^{\star \star \star}$ & $1 \cdot 1(1 \cdot 0)^{\star \star \star}$ \\
\hline Pain & $1.0(1.0)$ & $0 \cdot 5(0 \cdot 7)^{\star \star \star}$ & $0 \cdot 5(0 \cdot 7)^{\star \star \star}$ & $0.4(0 \cdot 8)^{\star \star \star}$ \\
\hline Regurgitation & $1.5(1 \cdot 1)$ & $0 \cdot 4(0 \cdot 6)^{\star \star \star}$ & $0.3(0.5)^{\star \star \star}$ & $0.5(0.7)^{\star \star \star}$ \\
\hline Total score & $5 \cdot 1(1 \cdot 8)$ & $2 \cdot 0(1 \cdot 6)^{\star \star \star}$ & $1 \cdot 7(1 \cdot 8)^{\star \star \star}$ & $1.9(2 \cdot 0)^{\star \star \star}$ \\
\hline
\end{tabular}

$\mathrm{n}$ : Number of patients taken into account for statistical analysis. Non-parametric variance analysis for repeated measures was calculated with the number of subjects available at six months (per protocol analysis).

a Subjective score was calculated by classifying patients lost to follow up and failure as bad results. ${ }^{\star \star \star} \mathrm{p}<0 \cdot 001$ categories (clinical improvement, failure, or relapse). Clinical improvement was defined as a score $\leq 3$, relapse as a score $>3$ and/or the need to perform an additional injection, and failure as a lack of improvement or a relapse after two injections. In ITT, patients lost to follow up were considered failures. Estimation of remission after a single injection of BT was determined by an actuarial method dividing the whole time range into 15 day periods.

Changes observed after BT injection (symptom score, manometric parameters, acid exposure, and scintigraphic data) were also evaluated on a per protocol basis by nonparametric analysis of variance for repeated measures.

Data are expressed as mean (SD) or median when appropriate. A search for factors predictive of therapeutic response was carried out using univariate analysis: Student's $t$ test was used for normally distributed quantitative variables (age, LOS pressure, diameter of oesophagus); the Mann-Whitney test for nonnormally distributed quantitative variables (duration of symptoms, weight loss, initial symptom score, magnitude of waves of oesophageal body contraction); and the $\chi^{2}$ test for binary qualitative variables (sex, previous pneumatic dilatation). In addition, an attempt was made to identify outcome predictors. Relationships were examined between clinical improvement and the results of functional investigations (LOS pressure, scintigraphy of liquids and solids at one and eight minutes). Spearman correlation coefficients were calculated between each of these variables and time, and then compared with the Spearman correlation coefficient calculated between symptom score and time. A p value $<0.01$ was considered significant given the multiplicity of tests used on the same data (Bonferroni correction).

\section{Results}

PATIENT CHARACTERISTICS AT INCLUSION Fifty five consecutive patients were enrolled by 12 centres between October 1994 and May 1995 (28 men, 27 women; mean age 53 years, range 19-78). Table 2 presents the main patient characteristics. Oesophageal $\mathrm{pH}$ monitoring was performed in 42 patients before BT. Median oesophageal acid exposure was 0.7 $(1 \cdot 8) \%$ (range $0 \cdot 0-10 \cdot 9 \%$ ). Two patients had abnormal acid exposure. Oesophageal scintigraphy was performed in 15 patients.

Upper gastrointestinal endoscopy detected no relevant abnormalities except food-salivary stasis in $24 / 55$ patients $(43.6 \%)$.

THERAPEUTIC RESULTS

No serious adverse effects were reported after the 73 injections (18 patients received two sets of injections). Sixteen patients $(22 \%)$ had transient $(<48$ hours) mild chest or epigastric pain after injection, 13 of whom had reported retrosternal pains before injection. As four patients were lost to follow up, 51/55 patients $(93 \%)$ completed the six month study. Table 3 
presents the clinical results. Patients with an initial weight loss showed a significant weight increase $(4 \cdot 2(3 \cdot 0) \mathrm{kg}, \mathrm{n}=23)$ at six months. The median delay for symptomatic improvement was two days (range 1-30). Among patients who had improvement after BT, $46 \%$ were improved 24 hours after injection.

At week 2, 41 patients showed clinical improvement $(74 \cdot 5 \%)$. Among the 14 patients with failure, three were excluded from the trial and 11 received a second injection before month 2. Two of these 11 patients showed clinical improvement at month 6 . At month 2, 38 patients showed clinical improvement $(69 \%)$, nine had relapse $(16 \%)$, and eight had failure (15\%). Among the 41 patients showing clinical improvement at week 2 , seven received a second injection between months 2 and 6; four of these seven patients showed clinical improvement at month 6 . At month 6,33 patients (27 with one injection) showed clinical improvement $(60 \%)$, five had a relapse $(9 \%)$, and $17 \mathrm{had}$ failure (31\%) (four were lost to follow up). The probability of clinical improvement at six months after one BT injection was $52 \%$ (fig 2). Overall, scores at month 6 were $\leq 2$ in 31 patients, $\leq 1$ in 22 patients, and null in eight patients.

Six of the 18 patients $(33 \%)$ who received a second injection achieved sustained clinical improvement at month 6 .

There were no significant differences between the seven centres which had five or more patients. The clinical improvement rate at month 6 ranged from $50 \%$ to $80 \%$.

CHANGES IN OESOPHAGEAL FUNCTION (table 4) In all patients but one, manometry showed the persistence of complete oesophageal aperistalsis (fig 3 shows changes in LOS pressure).

Among the 29 patients who had pH monitoring at two months, abnormal oesophageal acid exposure was recorded in only one (percentage of time less than $\mathrm{pH} 4: 0 \%$ at inclusion, $6.4 \%$ at two weeks, and $8 \cdot 4 \%$ at two months), and there were no symptoms of gastro-oesophageal reflux disease.

There was a statistically significant improvement in scintigraphic parameters (fig 4).

\section{OUTCOME PREDICTORS}

Therapeutic response was not significantly affected by age, sex $(p=0.51)$, previous pneumatic dilatation $(p=0.48)$, prior duration of symptoms, initial weight loss, initial score, initial LOS pressure, diameter of oesophagus, or amplitude of oesophageal contractions (table 5). These findings remained valid even when the five patients who had just relapsed at six months were considered as responders, in which case the trend towards an age difference between responders $(56.0(14.7)$ years, $n=38)$ and non-responders (47.6 (13.7) years, $n=17, p=0.053$ ) was strengthened. Clinical improvement at six months was more frequently observed in patients with vigorous achalasia $(15 / 22 ; 68.2 \%)$ than in those with classic achalasia $(18 / 33 ; 54.5 \%)$, but the

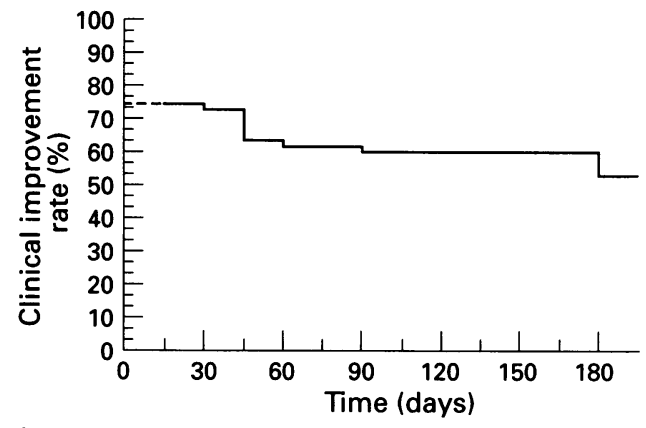

Patients at $41403332 \quad 31$ risk (n)

Figure 2: Probability of clinical improvement after a single intrasphincteric injection of botulinum toxin (actuarial method).

difference was not statistically significant (table 5).

Only Spearman correlation coefficients for scintigraphy of liquids at one minute $(p=0 \cdot 369$, $\mathrm{n}=49)$ and for symptom score $(p=-0.565$, $n=51)$ were not significantly different $(p>0.05$, absolute value). The other coefficients were significantly different, indicating that the time course between symptom score and the studied parameter was different.

\section{Discussion}

The results of the present study show that intrasphincteric injection of BT is a safe procedure, resulting in clinical improvement in $60 \%$ of patients with achalasia at six months. These results clearly confirm and extend those of Pasricha et al. ${ }^{89}$ Moreover, the lack of significantly different results between centres suggests that this therapeutic procedure is highly feasible for use in non-specialised centres.

The multicentre design of our study allowed us to enrol 55 consecutive patients within a relatively short period. With regard to age and disease characteristics, our study population was quite representative of achalasia and very similar to populations reported in other studies. ${ }^{3} 4$ 21-23 Interestingly, the marked weight loss noticed in two thirds of our patients

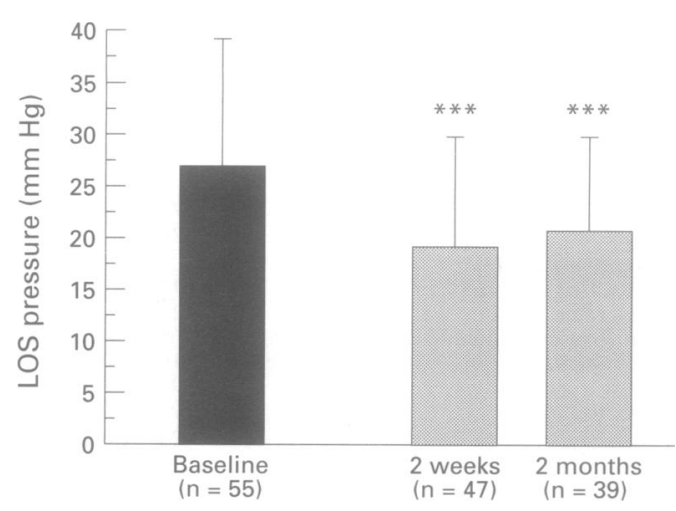

Figure 3: Mean (SD) pressure of the lower oesophageal sphincter (LOS) at baseline and two weeks and two months after injection of botulinum toxin $\left({ }^{\star *} p<0 \cdot 001\right)$. 

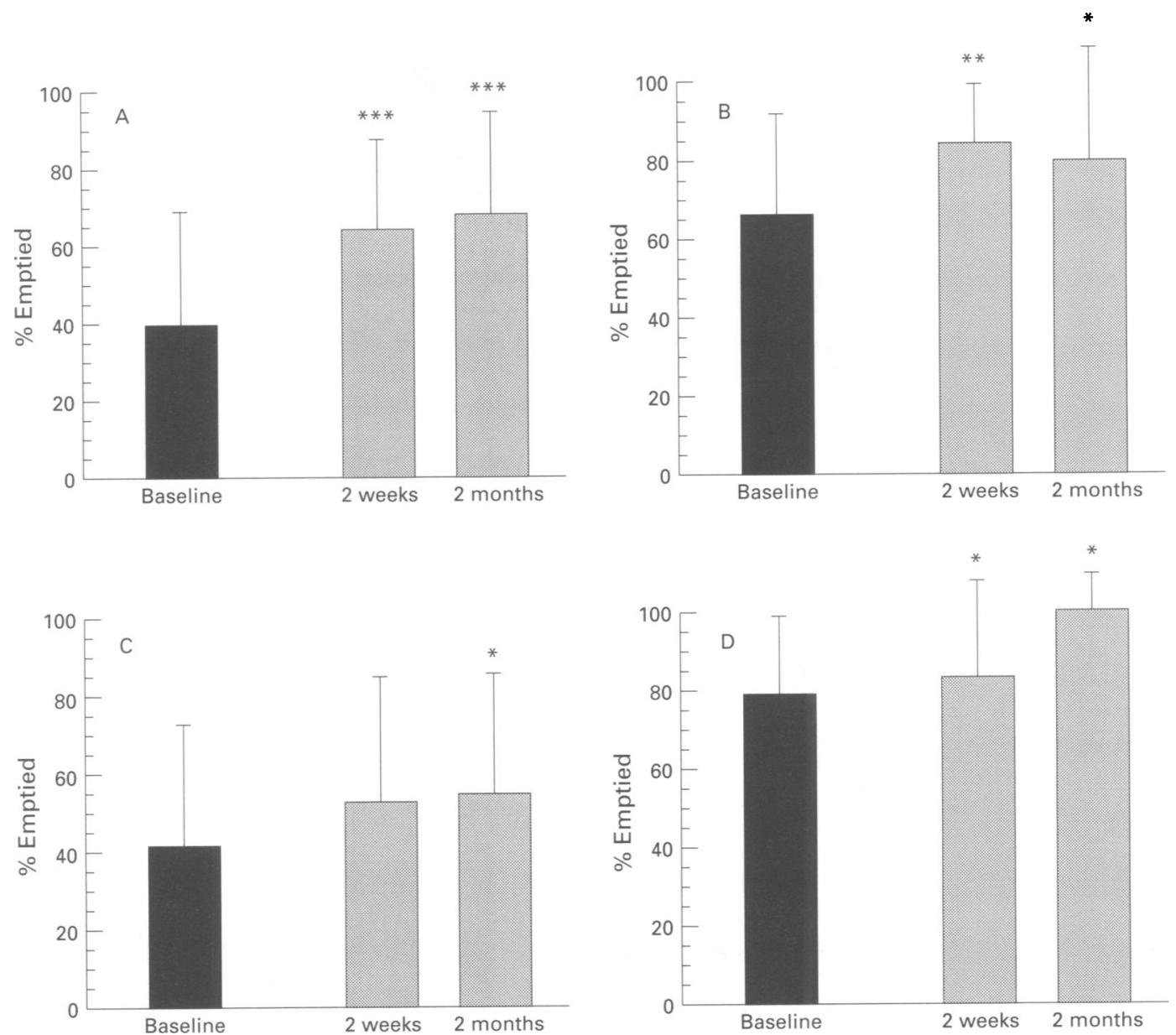

Figure 4: Mean (SD) percentage of liquid $(A$ and $B)$ and solid $(C$ and $D)$ isotopic meal emptied into the oesophageal region of interest at one $(A$ and $C)$ and eight minutes $(B$ and $D)$, at baseline and two weeks and two months after injection of botulinum toxin $(n=15)\left({ }^{\star} p<0.05 ;{ }^{\star *} p<0.01 ;{ }^{\star * *} p<0.001\right)$.

TABLE 4 Manometric, scintigraphic, and pH-metric data before and after intrasphincteric injection of botulinum toxin in patients with achalasia followed up at two weeks and two months

\begin{tabular}{llll}
\hline & Inclusion & 2 Weeks & 2 Months \\
\hline Manometric data & $(\mathrm{n}=55)$ & $(\mathrm{n}=47)$ & $(\mathrm{n}=39)$ \\
& $26 \cdot 8(12 \cdot 3)$ & $18 \cdot 9(10 \cdot 6)^{\star}$ & $20 \cdot 3(9 \cdot 2)^{\star}$ \\
$\begin{array}{l}\text { Lower oesophageal sphincter pressure } \\
\text { (mm Hg) mean (SD) }\end{array}$ & & & \\
$\begin{array}{l}\text { Percentage of LOS relaxations (median (range)) } \\
\text { Complete (\%) }\end{array}$ & $0(100)$ & $0(80) \dagger$ & $16(80) \dagger$ \\
Incomplete (\%) & $26(100)$ & $25(100) \dagger$ & $29(100) \dagger$ \\
Absent (\%) & $52(100)$ & $50(100) \dagger$ & $35(100)^{\star \star}$ \\
Oesophageal scintigraphy (fractional emptying \%) mean $(S D)$ & $39(30)$ & $64(23)^{\star}$ & $68(26)^{\star}$ \\
Liquids ( $\mathrm{n}=15)$ 1 min & $66(26)$ & $84(15)^{\star \star}$ & $79(25)^{\star \star \star \star}$ \\
Solids ( $\mathrm{n}=16) \quad 1$ min & $41(32)$ & $52(33) \dagger$ & $54(32)^{\star \star \star \star}$ \\
$\quad 8$ min & $79(20)$ & $83(21)^{\star \star \star \star}$ & $84(21)^{\star \star \star}$ \\
Oesophageal pH monitoringt (median (range)) & $(\mathrm{n}=21)$ & $(\mathrm{n}=21)$ & $(\mathrm{n}=21)$ \\
Percentage of time under pH 4 & $0 \cdot 1(3 \cdot 5)$ & $0 \cdot 2(6 \cdot 4)$ & $0 \cdot 2(8 \cdot 5)$ \\
\hline
\end{tabular}

$\mathrm{n}$ : Number of patients taken into account for statistical analysis.

n: Number of patients taken int ${ }^{\star}<0.001 ;$
significantly different.

TABLE 5 Baseline characteristics (mean (SD)) of responders and non-responders at six month assessment

\begin{tabular}{llll}
\hline & $\begin{array}{l}\text { Responders } \\
(n=33)\end{array}$ & $\begin{array}{l}\text { Non-responders } \\
(n=22)\end{array}$ & $p$ Value \\
\hline Age (y) & $55 \cdot 9(15 \cdot 2)$ & $49 \cdot 6(13 \cdot 7)$ & $0 \cdot 125$ \\
Prior duration of symptoms (m) & $40 \cdot 9(45 \cdot 5)$ & $37 \cdot 1(52 \cdot 0)$ & $0 \cdot 915$ \\
Weight loss (kg) & $5 \cdot 2(6 \cdot 4)$ & $7 \cdot 0(6 \cdot 7)$ & $0 \cdot 324$ \\
Symptomatic score & $4 \cdot 9(2 \cdot 0)$ & $5 \cdot 5(1 \cdot 4)$ & $0 \cdot 183$ \\
Lower oesophageal sphincter pressure (mm Hg) & $28 \cdot 0(12 \cdot 5)$ & $25 \cdot 3(12 \cdot 1)$ & $0 \cdot 429$ \\
Oesophageal diameter (cm) & $4 \cdot 6(1 \cdot 4)$ & $4 \cdot 1(1 \cdot 3)$ & $0 \cdot 260$ \\
Amplitude of waves (mm Hg) & $39 \cdot 5(34 \cdot 2)$ & $35 \cdot 3(32 \cdot 0)$ & $0 \cdot 562$ \\
Vigorous achalasia/classic achalasia & $15 / 18$ & $7 / 15$ & $0 \cdot 311$ \\
\hline
\end{tabular}

$(8.8 \mathrm{~kg})$ probably reflects the severity of achalasia in this series.

BT injections (80 units) were well tolerated, with no occurrence of serious side effects. Minor side effects reported by $22 \%$ of the patients consisted of either transient retrosternal or epigastric pain. This figure compares well with the $30 \%$ of side effects reported both in the placebo group and the BT group in the trial conducted by Pasricha et al. ${ }^{8}$ Thus, these transient episodes of pain are more likely to be related to the injection itself than to any direct toxicity of BT. Moreover, among the 16 patients who reported minor side effects, 13 already had retrosternal pain before injection. Pathological acid exposure may be present in achalasia without any reflux symptoms. ${ }^{24}$ However, in contrast to the results of other studies, ${ }^{25}{ }^{26}$ a high incidence of abnormal acid reflux was not observed either before or after BT injections.

Individual symptoms as well as symptom scores were clearly improved at every time point, and mean weight gain $(4.2 \mathrm{~kg}$ at six months) paralleled this therapeutic benefit. These results are once again close to those of Pasricha et al who found $64 \%$ of patients in remission at six months. ${ }^{8} 9$ Relief of symptoms occurred earlier and lasted longer than after BT injection in striated muscle, ${ }^{8911} 13$ suggesting that smooth muscle has greater sensitivity. 
Symptom relief was accompanied by a significant decrease in LOS pressure (for example a $31 \%$ drop at two months) after BT injection, although it remained above $20 \mathrm{~mm}$ $\mathrm{Hg}$. It has not been determined whether an increase in BT dosage could result in a more marked effect on LOS pressure. ${ }^{27}$ It is noteworthy however that a decrease in LOS pressure after pneumatic dilatation appears to be the best predictor of therapeutic response. ${ }^{3}$ Contrary to the findings of Pasricha et $a l^{9}$, in our series, the drop in LOS pressure after BT did not prove to be a reliable predictor of outcome.

It is also noteworthy that oesophageal emptying was markedly improved in many cases. In particular, the emptying of liquids (measured at one minute) was significantly correlated with symptom improvement.

Unlike Pasricha et $a l^{9}$, who observed better responses for patients over 50 years of age and for vigorous achalasia, we failed to detect any predictors of response to BT. Yet a trend was noted towards better responses in older patients and in those with vigorous achalasia. The fact that it fell short of statistical significance, especially for age, may reflect a type 2 error, even though a large number of patients was included in the study. More importantly, it should be emphasised that previous failure of pneumatic dilatation does not preclude response to BT. Therefore, these two techniques may actually broaden our therapeutic armamentarium rather than being competitive choices.

In conclusion, our series confirms that intrasphincteric injection of BT is a safe and highly feasible procedure which can easily be applied in non-specialised centres. The lack of significant side effects suggests that this treatment could be given on an outpatient basis, thereby reducing the cost of therapy. BT injection could be proposed as an initial treatment for patients with a high risk of complications with conventional procedures (pneumatic dilatation and surgery). Further studies are required to evaluate the potential for individualised treatment offered by higher BT doses in patients unresponsive to standard doses and to determine the as yet unknown long term effects of maintenance with repeated BT injections.

Despite the large number of patients required, multicentre controlled trials should be initiated now to compare BT with pneumatic dilatation and/or surgical treatment. In addition to the clinical improvement achieved, safety and duration of action as well as cost effectiveness are relevant end points in determining the most appropriate strategy. Moreover, the role of BT in patients who have failed to respond to pneumatic dilatation or surgery should be further evaluated.

This study was presented to the American Gastroenterological Association (San Francisco, California) and has appeared in abstract form (Gastroenterology 1996; 110: A86). The study was supported by a grant from the Fond de Recherche de la Société Nationale Française de Gastroentérologie. The authors thank
Allergan for supplying Botox ${ }^{k}$, Dr Pasricha for fruitful discussions, and the Nantes University Hospital for promoting the study.

1 Katz PO. Achalasia. In: Castell DO, Richter J, Dalton C, eds. Esophageal motility testing. New York: Elsevier, 1987 107-17.

2 Csendes A, Braghetto I, Henriquez A, Cortés C Late results of a prospective randomised study comparing forceful dilatation and oesophagomyotomy in patients with achalasia. Gut 1989; 30: 299-304

3 Eckardt VF, Aignherr C, Bernhard G. Predictors of outcome in patients with achalasia treated by pneumatic dilation. Gastroenterology 1992; 103: 1732-8.

4 Lamouliatte H, Zerbib F, Bernard PH, Cayla R, Stablo M, Quinton A. Traitement par dilatation pneumatique des achalasies de l'œsophage [abstract]. Gastroenterol Clin Bio 1993; 17: A245.

5 Schwartz HM, Cahow CE, Traube M. Outcome after perforation sustained during pneumatic dilatation for achalasia. Dig Dis Sci 1993; 38: 1409-13.

6 Vantrappen G, Hellemans J. Treatment of achalasia and related motor disorders. Gastroenterology 1980; 79: 144-54

7 Andreollo NA, Earlam RJ. Heller's myotomy for achalasia: is an added anti-reflux procedure necessary? $\mathrm{Br} \mathcal{F}$ Surg 1987; 74: 765-9.

8 Pasricha PJ, Ravich WJ, Hendrix TR, Sostre S, Jones B, Kalloo AN. Intrasphincteric botulinum toxin for the treatment of achalasia. N Engl f Med 1995; 332: 774-8.

9 Pasricha PJ, Rai R, Ravich WJ, Hendrix TR, Kalloo AN. Botulinum toxin for achalasia: long-term outcome and predictors of response. Gastroenterology 1996; 110: 1410-5.

10 Pasricha PJ, Ravich WJ, Hendrix TR, Sostre S, Kalloo AN, Jones B, et al. Treatment of achalasia with intrasphincteric injection of botulinum toxin: a pilot trial. Ann Intern Med 1994; 121: 590-1.

11 Elston JS. The clinical use of botulinum toxin. Semin Ophtalmol 1988; 3: 249-60.

12 Poulain B. Mécanisme d'action moléculaire de la toxine tétanique et des neurotoxines botuliques. Pathol Biol 1994 ; 2 : 173-82.

13 Jankovic J, Brin MF. Therapeutic uses of Botulinum toxin. N Engl F Med 1991; 324: 1186-94.

14 Pamphlett R. Early terminal and nodal sprouting of motor axons after botulinum toxin. 7 Neurol Sci 1989; 92: 181-92.

15 Schantz EJ, Johnson EA. Properties and use of botulinum toxin and other microbial neurotoxins in medicine. Microbiol Rev 1992; 56: 80-99.

16 MacKenzie I, Burnstock G, Dolly JO. The effects of purified botulinum neurotoxin type $A$ on cholinergic adrenergic and non-adrenergic, atropine-resistant autonomicneuromuscular transmission. Neuroscience 1982; 7: 997-1006.

17 Paul ML, Cook MA. Lack of effect of botulinum toxin on nonadrenergic, noncholinergic inhibitory response of the guinea pig fundus in vitro. Can $\mathcal{F}$ Physiol Pharmacol 1980; 58: 88-92.

18 Pasricha PJ, Ravich WJ, Kalloo AN. Effects of intrasphincteric botulinum toxin on the lower esophageal sphincter in piglets. Gastroenterology 1993; 105: 1045-9.

19 Devière J, Dunham F, Rickaert F, Bourgeois N, Cremer N. Endoscopic ultrasonography in achalasia. Gastroenterology 1989; 96: 1210-3.

20 Ziegler $\mathrm{K}$, Zimmer $\mathrm{T}$. The role of endoscopic ultrasonography in esophageal motility disorders. Endoscopy 1992; 24: 338-41.

21 Howard PJ, Maher L, Pryde A, Cameron EWJ, Heading RC. Five-year prospective study of the incidence, clinical features, and diagnosis of achalasia in Edinburgh. Gut 1992; 33: 1011-5.

$22 \mathrm{Kim} \mathrm{CH}$, Cameron AJ, Hsu JJ, Talley NJ, Trastek VF Pairolero PC, et al. Achalasia: prospective evaluation of relationship between lower esophageal sphincter pressure, esophageal transit, and esophageal diameter and symptoms in response to pneumatic dilation. Mayo Clin Proc 1993; 68: 1067-73.

23 Jaïs F, Bruley des Varannes S, Simon J, Gasser $P$, Le Bodic L, Galmiche JP. La présentation clinique et la réponse thérapeutique des formes vigoureuses et non vigoureuses d'achalasie sont similaires [abstract]. vastroenterol Clin Biol 1994; 18: A19.

24 Shoenut JP, Micflikier AB, Yaffe CS, Den Boer B Teskey JM. Reflux in untreated achalasia patients. $\mathcal{F}$ Clin Teskey JM. Reflux in untreated

25 Kotfila R, Camp R, Trudeau W. Botulinum toxin (Botox) injection in achalasia patients failing pneumatic dilation and medical therapy [abstract]. Gastroenterology 1995 108: A136.

26 Waterfall WE, Tougas G, Fachnie B, Chauhan U. Clinical and manometric response to Botulinum toxin (Botox) used as primary treatment for achalasia [abstract]. Gastroenterology 1995; 108: A255.

27 Kozarek RA, Gelfand MD, Patterson DJ, Brandabur JJ Ball DJ, Bredfelt J, et al. Prospective trial of 50 vs $100 \mathrm{IU}$ of type A Botulinum toxin for idiopathic achalasia [abstract]. Gastroenterology 1996; 110: A162. 